\title{
Resistance to tetracycline and $\beta$-lactams and distribution of resistance markers in enteric microorganisms and pseudomonads isolated from the oral cavity
}

\author{
Marcelle Marie Buso RAMOS ${ }^{1}$, Ellen Cristina GAETTI-JARDIM², Elerson GAETTI-JARDIM JUNIOR ${ }^{3}$
}

1- Undergraduate student, School of Dentistry of Araçatuba, São Paulo State University-UNESP.
2- DDS, MSc Student, Department of Pathology and Clinical Propedeutics, School of Dentistry of Araçatuba, São Paulo State University-UNESP.
3- DDS, MSc, PhD, Associate Professor, Department of Pathology and Clinical Propedeutics, School of Dentistry of Araçatuba, São Paulo State University-UNESP.

Corresponding address: Prof. Dr. Elerson Gaetti Jardim Júnior - Faculdade de Odontologia de Araçatuba-UNESP - Rua Jose Bonifácio, 1193 - $16015-050$ Araçatuba, SP, Brazil - Phone: +55-18-3636-2797/ Fax: +55-18-3636-3224 - e-mail: egaettij@foa.unesp.br or gaettijardim@gmail.com

Received: August 20, 2009 - Accepted: February 19, 2010

\section{ABSTRACT}

This study evaluated the occurrence of enteric bacteria and pseudomonads resistant to
tetracycline and $\beta$-lactams in the oral cavity of patients exhibiting gingivitis $(n=89)$,
periodontitis ( $n=79)$, periodontally healthy $(n=50)$ and wearing complete dentures $(n=41)$.
Microbial identification and presence of resistance markers associated with the production
of $\beta$-lactamases and tetracycline resistance were performed by using biochemical tests
and PCR. Susceptibility tests were carried out in 201 isolates of enteric cocci and rods.
Resistance to ampicillin, amoxicillin/clavulanic acid, imipenem, meropenem and tetracycli-
ne was detected in $57.4 \%, 34.6 \%, 2.4 \%, 1.9 \%$ and $36.5 \%$ of the isolates, respectively.
$\beta$-lactamase production was observed in $41.2 \%$ of tested microorganisms, while the most
commonly found $\beta$-lactamase genetic determinant was gene bla TEM. Tetracycline resistance
was disseminated and a wide scope of tet genes were detected in all studied microbial genus.

Key words: Oral cavity. Enteric bacteria. PCR.

\section{INTRODUCTION}

The oral microbiota is composed of more than 500 different microbial species, most of them associated with oral health. However, sometimes the balance between the host's immune system and microbial virulence is lost and opportunistic infections may arise. Hence, oral infectious diseases have been frequently associated with alterations in the host' immune system, poor oral hygiene, denutrition, and alcoholism ${ }^{18}$.

Associations between the occurrence of opportunistic and superinfecting pathogens with patients exhibiting different periodontal status $^{2}$ or wearing complete dentures ${ }^{4}$ have been established. However, the role enteric bacteria and pseudomonads play in the etiology of periodontal disease needs further studies. In edentulous patients wearing complete dentures, the presence of enteric microorganisms may be associated with development of mucositis and usually reflects poor hygiene standards ${ }^{4}$.

Suppression of the oral microbiota by abusive or intensive use of antibiotics may facilitate a persistent colonization of the oral cavity by these opportunistic microorganisms ${ }^{18}$. These microorganisms may spread to microbial populations in nosocomial infections or to the dental biofilm, acting as reservoirs for antibiotic resistance genes ${ }^{7}$.

Tetracyclines were among the most widely used drugs in dentistry in the 80 's. Their 
effects on anaerobes and Aggregatibacter actinomycetemcomitans made these drugs the first choice in the treatment of aggressive periodontitis and necrotizing periodontitis. â-lactams, such as ampicillin, amoxicillin, cefoxitin and others constitute the basis of antimicrobial treatment of head and neck infections. However, microbial resistance to these drugs has compromised the efficacy of this therapy and the dissemination of resistance genes among oral microorganisms needs further investigation, as the oral cavity may harbor some multiresistant microorganisms, particularly enteric rods and cocci.

Thus, the aim of this study was to evaluate the presence of antimicrobial resistance genes (tetracycline and $\beta$-lactams) in enteric microorganisms isolated from the oral cavity of patients with gingivitis, periodontitis, periodontally healthy patients and patients wearing complete dentures, determining the distribution of most common $\beta$-lactamase markers and tetracycline resistance markers.

\section{MATERIAL AND METHODS}

\section{Microorganisms and microbial identification}

Enteric microorganisms were isolated from 250 patients ( 84 males and 166 females), mean age 43.03 years, within an 10-year follow-up period (1998-2008) at the School of Dentistry of Araçatuba, São Paulo State University (UNESP), Brazil. Forty-one patients wore complete dentures, 89 exhibited gingivitis, 70 chronic periodontitis and 50 were periodontally healthy. A written consent form was signed by all patients included in this study, which was approved by the Institutional Review Board of School of Dentistry of Araçatuba (Proc.27/2000 and 34/2006).

Microbial isolation was performed as previously described ${ }^{6}$. The isolates were identified by Gram staining, colony morphology on agar plates, catalase assay, and biochemical identification kits (BioMérieux, Marcy le' Etoile, France). A total of 201 enteric microorganisms and pseudomonads were submitted to susceptibility tests, as follows: Burkholderia cenocepacia (5 isolates), Citrobacter freundii (7 isolates), Enterobacter cloacae (18 isolates), E. intermedius (6 isolates), E. sakazakii (9 isolates), Enterococcus sp. (18 isolates), E. faecalis (31 isolates), E. faecium (8 isolates), Escherichia coli (6 isolates), Klebsiella oxytoca (11 isolates), K. pneumoniae ( 3 isolates), Morganella morganii (17 isolates), Pantoea agglomerans (7 isolates), Proteus mirabilis (5 isolates), P. vulgaris (7 isolates), Providencia alcalifaciens (6 isolates), Pseudomonas aeruginosa (15 isolates), P. fluorescens (4 isolates), Serratia sp. (9 isolates), and S. liquefaciens (9 isolates).

All isolates were examined for susceptibility to tetracycline, ampicillin, amoxicillin/clavulanic acid, cefoxitin, cephalothin, imipenem and meropenem by the agar dilution method. When the Clinical Laboratory and Standards Institute (CLSI) antimicrobial breakpoints were not established, the breakpoints adopted by the British Society for Antimicrobial Chemotherapy (BSAC) were followed. Mueller-Hinton agar (MHA) was used for all isolates.

In the susceptibility tests, five pure colonies of each bacterial strain were inoculated into $2 \mathrm{ml}$ of sterile Mueller Hinton broth and incubated at $37^{\circ} \mathrm{C}$ for $12-24 \mathrm{~h}$. Then, the turbidity was adjusted to match the 0.5 McFarland turbidity standard. The bacterial inocula were standardized in $10^{5}$ cells and transferred to Mueller-Hinton agar plates containing the antimicrobial agent and control plates (without drugs), using a Steer's replicator (Cefar Ltda., SP, Brazil). The test and control agar plates were incubated aerobically at $37^{\circ} \mathrm{C}$, for $48 \mathrm{~h}$.

Antimicrobials were tested in two-fold dilution series ranging from $0.06 \mu \mathrm{g} / \mathrm{mL}$ to $256 \mu \mathrm{g} / \mathrm{mL}$. After incubation, the organisms were classified as sensitive or resistant, according to CLSI and BSAC guidelines. E. coli ATCC 25922, S. aureus ATCC 29213, P. aeruginosa ATCC 27853, and E. faecalis ATCC 29212 were used in the assays involving facultative anaerobes.

\section{Detection of $\beta$-lactamases}

$\beta$-Lactam-resistant isolates were also tested for $\beta$-lactamase activity by both chromogenic cephalosporin and biological method ${ }^{5}$. These two methods were performed because nitrocefinbased $\beta$-lactamase assays have not proven 
useful in detecting $\beta$-lactamase production by some microorganisms. In all tests, $S$. aureus ATCC 29213 was used as the positive control for $\beta$-lactamase production.

\section{Distribution of antimicrobial resistance determinants}

Bacterial DNA from each $\beta$-lactamase producers placed in sterile ultra-pure water was obtained by using a QIAamp DNA Mini Kit (Qiagen, Hilden, Germany). DNA concentrations were determined with a spectrophotometer at $A_{260} \mathrm{~nm}$ (Model DU640, Beckman Instruments, Richmond, Wash, USA).

Tetracycline-resistant isolates were screened for tetracycline resistance genes ${ }^{1,16} \operatorname{tet}(A)$, $\operatorname{tet}(\mathrm{B}), \operatorname{tet}(\mathrm{C}), \operatorname{tet}(\mathrm{D}), \operatorname{tet}(\mathrm{E}), \operatorname{tet}(\mathrm{G}), \operatorname{tet}(\mathrm{K})$, $\operatorname{tet}(\mathrm{L}), \operatorname{tet}(\mathrm{M}), \operatorname{tet}(\mathrm{O}), \operatorname{tet}(\mathrm{Q})$, tet $(\mathrm{S})$, and $\operatorname{tet}(\mathrm{T})$, while $\beta$-lactam-resistant microorganisms were screened for $b / a_{\mathrm{TEM}^{\prime}} b / a_{\mathrm{CTX}-\mathrm{M}}$ and $b / a_{\mathrm{SHV}}$ genes $^{3,8}$ using specific primer pairs. DNA amplification was performed in a DNA thermal cycler (AmpliTherm Thermal Cycler, Madison, WI, USA). The amplification conditions were $94^{\circ} \mathrm{C}$ ( $5 \mathrm{~min}$ ) for initial denaturation, followed by 35 cycles at $94^{\circ} \mathrm{C}$ for $1 \mathrm{~min}$, annealing temperature adequate for each primer pair for $1 \mathrm{~min}$ and $72^{\circ} \mathrm{C}$ for $1 \mathrm{~min}$ for extension; then $72^{\circ} \mathrm{C}$ for 5 min to allow final DNA extension.

\section{RESULTS}

In relation to susceptibility to antimicrobial drugs, significant levels of resistance were observed for all $\beta$-lactams, except for imipenem and meropenem, which presented $2.4 \%$ and $1.9 \%$ of resistance, respectively. Resistance to ampicillin, and cephalothin were detected in $57.4 \%$, and $41.7 \%$ of tested bacteria, especially Pseudomonadaceae and Enterobacteriaceae. Out

Table 1- Resistance to $\beta$-lactams and tetracycline in enteric bacteria and pseudomonads

\begin{tabular}{|c|c|c|c|c|c|c|c|c|}
\hline \multirow[t]{2}{*}{ TAXON (N) } & \multirow[b]{2}{*}{ AM } & \multirow[b]{2}{*}{ AMC } & \multicolumn{4}{|c|}{ Resistance prevalence N (\%) } & \multirow[b]{2}{*}{ TE } & \multirow{2}{*}{$\begin{array}{l}\beta \text {-lactamase } \\
\text { production }\end{array}$} \\
\hline & & & CF & $\mathrm{CP}$ & IM & ME & & \\
\hline A. bamanii (10) & $6(60.0)$ & $1(10.0)$ & $2(20.0)$ & $3(30.0)$ & $0(0.0)$ & $0(0.0)$ & $2(20.0)$ & $6(60.0)$ \\
\hline B. cenocepacia (5) & $4(80.0)$ & $2(40.0)$ & $1(20.0)$ & $1(20.0)$ & $0(0.0)$ & $0(0.0)$ & $2(40.0)$ & $2(40.0)$ \\
\hline C. freundii (7) & $4(57.1)$ & $2(28.6)$ & $3(42.9)$ & $3(42.9)$ & $0(0.0)$ & $0(0.0)$ & $2(28.6)$ & $4(57.1)$ \\
\hline E. cloacae (18) & $14(77.8)$ & $9(50.0)$ & $11(61.1)$ & $11(61.1)$ & $0(0.0)$ & $0(0.0)$ & $1(5.6)$ & $13(72.2)$ \\
\hline E. intermedius (6) & $2(33.3)$ & $2(33.3)$ & $0(0.0)$ & $0(0.0)$ & $0(0.0)$ & $0(0.0)$ & $1(16.7)$ & $2(33.3)$ \\
\hline E. sakazakii (9) & $4(44.4)$ & $1(11.1)$ & $2(22.2)$ & $9(100.0)$ & $0(0.0)$ & $0(0.0)$ & $1(11.1)$ & $4(44.4)$ \\
\hline Enterococcus sp. (18) & $4(22.2)$ & $0(0.0)$ & $6(33.3)$ & $7(38.9)$ & $0(0.0)$ & $0(0.0)$ & 7 (38.9) & $0(0.0)$ \\
\hline E. faecalis (31) & $6(19.4)$ & $0(0.0)$ & $3(9.7)$ & $12(38.7)$ & $0(0.0)$ & $0(0.0)$ & $19(61.3)$ & $0(0.0)$ \\
\hline E. faecium (8) & $4(50.0)$ & $0(0.0)$ & $4(50.0)$ & $4(50.0)$ & $2(25.0)$ & $1(12.5)$ & $3(37.5)$ & $0(0.0)$ \\
\hline E. coli $(6)$ & $4(66.7)$ & $1(16.7)$ & $0(0.0)$ & $0(0.0)$ & $0(0.0)$ & $0(0.0)$ & $1(16.7)$ & $4(66.7)$ \\
\hline K. oxytoca (11) & $7(63.6)$ & $5(45.5)$ & $1(9.1)$ & $3(27.3)$ & $0(0.0)$ & $0(0.0)$ & $0(0.0)$ & $6(54.5)$ \\
\hline K. pneumoniae (3) & $3(100.0)$ & $2(66.7)$ & $0(0.0)$ & $0(0.0)$ & $0(0.0)$ & $0(0.0)$ & $0(0.0)$ & $3(100.0)$ \\
\hline M. morganii (17) & $12(70.6)$ & $9(52.9)$ & $5(29.4)$ & $9(52.9)$ & $1(5.9)$ & $1(5.9)$ & $7(41.2)$ & $9(52.9)$ \\
\hline P. agglomerans (7) & $6(85.7)$ & $6(85.7)$ & $3(42.9)$ & $3(42.9)$ & $0(0.0)$ & $0(0.0)$ & $2(28.5)$ & $6(85.7)$ \\
\hline P. mirabilis (5) & $3(60.0)$ & $0(0.0)$ & $0(0.0)$ & $2(40.0)$ & $0(0.0)$ & $0(0.0)$ & $2(40.0)$ & $4(80.0)$ \\
\hline P. vulgaris (7) & $5(71.4)$ & $2(28.6)$ & $1(14.3)$ & $1(14.3)$ & $0(0.0)$ & $0(0.0)$ & $1(14.3)$ & $5(71.4)$ \\
\hline P. alcalifaciens (6) & $4(66.7)$ & $4(66.7)$ & $1(16.7)$ & $2(33.3)$ & $0(0.0)$ & $0(0.0)$ & $4(66.7)$ & $4(66.7)$ \\
\hline$P$. aeruginosa (15) & $13(86.7)$ & $13(86.7)$ & $8(53.3)$ & $9(60.0)$ & $2(13.3)$ & $2(13.3)$ & $11(73.3)$ & $3(20.0)$ \\
\hline P. fluorescens (4) & $3(75.8)$ & $3(75.0)$ & $0(0.0)$ & $1(25.0)$ & $0(0.0)$ & $0(0.0)$ & $1(25.0)$ & $1(25.0)$ \\
\hline S. liquefaciens (9) & $6(66.7)$ & $6(66.7)$ & $2(22.2)$ & $3(33.3)$ & $0(0.0)$ & $0(0.0)$ & $5(55.6)$ & $6(66.7)$ \\
\hline Serratia sp. (9) & $7(77.8)$ & $5(55.6)$ & $5(55.6)$ & $5(55.6)$ & $0(0.0)$ & $0(0.0)$ & $5(55.6)$ & $6(66.7)$ \\
\hline Total (211) & $121(57.4)$ & $73(34.6)$ & $58(27.5)$ & $88(41.7)$ & $5(2.4)$ & $4(1.9)$ & $77(36.5)$ & $87(41.3)$ \\
\hline
\end{tabular}

$\mathrm{AM}=$ ampicillin; $\mathrm{AMC}=$ amoxicillin/clavulanic acid $\mathrm{CF}=$ cefoxitin $; \mathrm{CP}=$ cephalotin; $\mathrm{IM}=$ imipenem; $\mathrm{ME}=$ meropenem; $\mathrm{TE}=$ tetracycline 
Table 2- Distribution of tetracycline and $\beta$-lactam resistance genes in resistant Gram-negative isolates

\begin{tabular}{|c|c|c|c|c|c|c|c|c|c|}
\hline \multirow{2}{*}{$\begin{array}{l}\text { Resistant } \\
\text { microorganisms }\end{array}$} & \multicolumn{8}{|c|}{ Frequency of antimicrobial resistance determinants $\mathrm{N}(\%)$} & \multirow[b]{2}{*}{$\operatorname{tet}(\mathrm{M})$} \\
\hline & $b / a_{\mathrm{TEM}}$ & $b a_{\text {CTX-M }}$ & $b a_{\mathrm{SHV}}$ & $\operatorname{tet}(\mathrm{A})$ & $\operatorname{tet}(\mathrm{B})$ & $\operatorname{tet}(\mathrm{C})$ & $\operatorname{tet}(\mathrm{D})$ & tet(E) & \\
\hline A. bamanii & $3(50.0)$ & $0(0.0)$ & $3(50.0)$ & $0(0.0)$ & $2(100.0)$ & $0(0.0)$ & $0(0.0)$ & $0(0.0)$ & $0(0.0)$ \\
\hline B. cenocepacia & $0(0.0)$ & $0(0.0)$ & $1(50.0)$ & $0(0.0)$ & $0(0.0)$ & $0(0.0)$ & $0(0.0)$ & $0(0.0)$ & $0(0.0)$ \\
\hline C. freundii & $1(25.0)$ & $0(0.0)$ & $1(25.0)$ & $1(50)$ & $0(0.0)$ & $0(0.0)$ & $1(50.0)$ & $0(0.0)$ & $0(0.0)$ \\
\hline E. cloacae & $5(35.7)$ & $1(7.1)$ & $3(21.5)$ & $0(0.0)$ & $1(100.0)$ & $0(0.0)$ & $0(0.0)$ & $0(0.0)$ & $0(0.0)$ \\
\hline E. intermedius & $2(100.0)$ & $0(0.0)$ & $0(0.0)$ & $0(0.0)$ & $1(100.0)$ & $0(0.0)$ & $0(0.0)$ & $0(0.0)$ & $0(0.0)$ \\
\hline E. sakazakii & $2(50.0)$ & $0(0.0)$ & $2(50.0)$ & $0(0.0)$ & $0(0.0)$ & $1(100.0)$ & $0(0.0)$ & $0(0.0)$ & $0(0.0)$ \\
\hline E. coli & $1(25.0)$ & $0(0.0)$ & $0(0.0)$ & $0(0.0)$ & $0(0.0)$ & $0(0.0)$ & $0(0.0)$ & $1(100.0)$ & $0(0.0)$ \\
\hline K. oxytoca & $1(14.3)$ & $1(14.3)$ & $1(14.3)$ & $0(0.0)$ & $2(100.0)$ & $0(0.0)$ & $0(0.0)$ & $0(0.0)$ & $0(0.0)$ \\
\hline K. pneumoniae & $0(0.0)$ & $0(0.0)$ & $3(75.0)$ & $0(0.0)$ & $0(0.0)$ & $2(100)$ & $0(0.0)$ & $0(0.0)$ & $0(0.0)$ \\
\hline M. morganii & $7(58.3)$ & $1(8.3)$ & $4(33.3)$ & $1(14.3)$ & $3(42.9)$ & $0(0.0)$ & $0(0.0)$ & $0(0.0)$ & $0(0.0)$ \\
\hline P. agglomerans & $0(0.0)$ & $0(0.0)$ & $4(66.7)$ & $0(0.0)$ & $2(100.0)$ & $0(0.0)$ & $0(0.0)$ & $0(0.0)$ & $0(0.0)$ \\
\hline P. mirabilis & $0(0.0)$ & $0(0.0)$ & $1(25.0)$ & $1(50.0)$ & $0(0.0)$ & $0(0.0)$ & $0(0.0)$ & $0(0.0)$ & $1(50.0)$ \\
\hline P. vulgaris & $2(40.0)$ & $0(0.0)$ & $1(20.0)$ & $1(100.0)$ & $0(0.0)$ & $0(0.0)$ & $0(0.0)$ & $0(0.0)$ & $0(0.0)$ \\
\hline P. alcalifaciens & $2(50.0)$ & $0(0.0)$ & $0(0.0)$ & $0(0.0)$ & $2(50.0)$ & $0(0.0)$ & $0(0.0)$ & $1(25.0)$ & $1(25.0)$ \\
\hline$P$. aeruginosa & $0(0.0)$ & $0(0.0)$ & $0(0.0)$ & $5(54.5)$ & $1(9.09)$ & $0(0.0)$ & $0(0.0)$ & $5(45.45)$ & $0(0.0)$ \\
\hline P. fluorescens & $0(0.0)$ & $0(0.0)$ & $0(0.0)$ & $1(50.0)$ & $0(0.0)$ & $0(0.0)$ & $0(0.0)$ & $1(50.0)$ & $0(0.0)$ \\
\hline S. liquefaciens & $2(40.0)$ & $0(0.0)$ & $1(20.0)$ & $3(60.0)$ & $0(0.0)$ & $0(0.0)$ & $2(40.0)$ & $0(0.0)$ & $0(0.0)$ \\
\hline Serratia sp. & $4(57.1)$ & $0(0.0)$ & $1(14.3)$ & $3(60.0)$ & $0(0.0)$ & $0(0.0)$ & $2(40.0)$ & $0(0.0)$ & $0(0.0)$ \\
\hline Total & $32(29.9)$ & $3(2.8)$ & $25(23.4)$ & $12(25.0)$ & $10(20.8)$ & $3(6.3)$ & $5(10.4)$ & $6(12.5)$ & $2(4.2)$ \\
\hline
\end{tabular}

Table 3- Distribution of tetracycline, ampicillin and gentamicin resistance genes in enterococci resistant to these antimicrobials

\begin{tabular}{|c|c|c|c|c|c|c|}
\hline \multirow[t]{3}{*}{ Resistant strains } & \multicolumn{6}{|c|}{ Frequency of antimicrobial resistance determinants $\mathrm{N}(\%)$} \\
\hline & $b / a_{\mathrm{TEM}} / \boldsymbol{b} / a_{\mathrm{CTX}-\mathrm{M}} / \boldsymbol{b} / a_{\mathrm{SHV}}$ & & & & & \\
\hline & & tet $(\mathrm{K})$ & tet (L) & tet $(\mathrm{M})$ & tet $(0)$ & tet (S) \\
\hline Enterococcus sp. & $0(0.0)$ & $3(42.9)$ & $1(14.3)$ & $2(28.6)$ & $1(14.3)$ & $0(0.0)$ \\
\hline E. faecalis & $0(0.0)$ & $6(31.6)$ & $2(10.5)$ & $7(36.8)$ & $3(15.8)$ & $1(5.3)$ \\
\hline E. faecium & $0(0.0)$ & $3(66.7)$ & $0(0.0)$ & $1(33.3)$ & $0(0.0)$ & $0(0.0)$ \\
\hline Total & $0(0.0)$ & $10(34.5)$ & $1(3.5)$ & $7(24.1)$ & $2(6.9)$ & $3(10.3)$ \\
\hline
\end{tabular}

of 121 bacterial isolates resistant to ampicillin or amoxicillin, 87 were $\beta$-lactamase producers of $(41.2 \%$ of the isolated bacteria and $72.9 \%$ of ampicillin-resistant isolates). The production of these hydrolytic enzymes seems to be the major mechanism of resistance to $\beta$-lactams, excluding most pseudomonads, and enterococci, where $\beta$-lactamases were not detected (Table 1 ).

Most of $\beta$-lactamase Gram-negative producers harbored $\beta$-lactamases. The detection of antimicrobial resistance determinants evidenced that $29.9 \%$ of Gram-negative isolates resistant to ampicillin harbored bla ${ }_{\mathrm{TEM}}$ genes, while bla ${ }_{\mathrm{SHV}}$ and bla $_{\text {СтХ-м }}$ were detected in $23.4 \%$ and $2.8 \%$ of the resistant isolates, respectively (Table 2 ).
These genes were not detected in enterococci (Table 3).

Resistance to tetracycline was also widely disseminated in the microbial enteric strains and $36.5 \%$ of tested microorganisms were resistant. The presence of tetracycline resistance determinants was widely disseminated among resistant Gram-negative isolates and enterococci. $\operatorname{Tet}(\mathrm{A})$ and $\operatorname{tet}(\mathrm{B})$ were the most common in Gram-negative bacteria; while tet $(\mathrm{K})$, tet( $\mathrm{M})$ and tet $(\mathrm{O})$ were predominant in resistant enterococci. $\operatorname{Tet}(\mathrm{G})$, tet( $\mathrm{Q})$ and $\operatorname{tet}(\mathrm{T})$ were not detected. 


\section{DISCUSSION}

Enteric bacteria and pseudomonads have been involved in many oral and extra-oral infections, and some studies have evidenced that the oral cavity may act as a reservoir of enteric microorganisms and their virulence genes ${ }^{1,6,7}$.

In spite of the small participation of enteric bacteria and pseudomonads in the total microbial load present in the gingival sulcus, supragingival biofilm, saliva and other sites of the oral cavity, the occurrence of these pathogens should not be neglected ${ }^{7}$. Antimicrobial resistance surveillance programs have provided sufficient data about antimicrobial susceptibility of clinically relevant enteric bacteria and pseudomonads from nosocomial infections and environment ${ }^{14,17}$, although few reports describe the antimicrobial susceptibility of these organisms isolated from the oral cavity ${ }^{2}$. In addition, information about the genetic determinants associated with this resistance is not clarified yet and most available data regards nosocomial infections, as mentioned above.

$\beta$-Lactam agents such as penicillins, cephalosporins, monobactams and carbapenems are among the most frequently prescribed antibiotics worldwide. In Gram-negative pathogens, $\beta$-lactamases remain the most important factor to $\beta$-lactam resistance, and their increasing prevalence, as well as their alarming evolution seems to be directly linked to their clinical use ${ }^{14}$.

In the present study, the genetic bases of $\beta$-lactamase production in enteric Gram-negative rods were mainly associated with bla ${ }_{\text {TЕM }}$ gene, which evidenced a noticeable dissemination among Gram-negative enteric bacteria ${ }^{10,19}$. Presence of $\beta$-lactamase genetic markers was significantly more pronounced in our study than previously reported in literature, even though the distribution of particular determinants in $\beta$-lactamase-producer strains was similar ${ }^{10,19}$.

However, the introduction of new $\beta$-lactams with different activity spectra has led to a selection of different genes and mutations that confer resistance to these drugs, especially $\beta$-lactamase-producers, mainly in members of family Enterobacteriaceae. In this family, most $\beta$-lactamase producers harbor $b / a_{\mathrm{TEM}}, b / a_{\mathrm{SHV}}$ and bla $_{\text {CTX-M }}$ resistance determinants ${ }^{14}$. Thus, the distribution of these resistance markers in enteric microorganisms distributed in the dental biofilm and mucosal surfaces remains unclear.

Therapeutic options for infections caused by Gram-negative organisms expressing $\beta$-lactamases are limited because these organisms are usually resistant to all $\beta$-lactam antibiotics, except the carbapenems. Several families of $\beta$-lactamases from Gram-negative organisms were identified, but no phenotypic test can differentiate them, impairing surveillance and epidemiological studies ${ }^{13}$.

The genes screened in the $\beta$-lactamase family represent only a small part of the cellular defense mechanisms that prokaryotes developed to avoid the action of $\beta$-lactams. Enterobacteriaceae isolates that exhibited uncertain identification by PCR were later classified as K. oxytoca, Enterobacter spp. and $C$. freundii due to detection markers of $\beta$-lactam resistance ${ }^{8}$. Moreover, $K$. oxytoca strains are known to express specific class $A \beta$-lactamases that were not considered in this study; while the resistance to $\beta$-lactams in Enterobacter sp. and C. freundii is generally attributed to the expression of chromosomal AmpC $\beta$-lactamases, as also described to some pseudomonads ${ }^{9}$. Possibly, these lactamases may be responsible for the $\beta$-lactam resistance phenotype, specifically to penicillins and narrowspectrum cephalosporins, registered in some isolates affiliated to these genera.

Enterococci in general and E. faecium in particular, are intrinsically more resistant to penicillin and ampicillin than the other streptococci. Ampicillin resistance in E. faecium is due to expression of the low-affinity class $B$ penicillin-binding protein 5 (PBP5). Early studies suggested that higher levels of ampicillin resistance in $E$. faecium were achieved by increasing levels of PBP 5 expression. More commonly, mutations that are presumed to lower the affinity for $\beta$-lactam antibiotics have been identified within $p b p 5$ genes of highly resistant clinical isolates ${ }^{15}$. The results of the present investigation also suggested that enterococcal 
resistance to $\beta$-lactams, especially ampicillin, is not related to gene $b / a_{\text {TEM }}$ as this gene and $\beta$-lactamase activities were not detected.

Tetracycline resistance was also often observed. The most common genetic determinants of tetracycline resistance are represented by genes tet, which can be separated into genes that encode efflux proteins, especially genes $\operatorname{tet}(\mathrm{A}), \operatorname{tet}(\mathrm{B}), \operatorname{tet}(\mathrm{C}), \operatorname{tet}(\mathrm{D}), \operatorname{tet}(\mathrm{E}), \operatorname{tet}(\mathrm{G})$, tet $(\mathrm{I})$, tet $(\mathrm{K})$, and tet $(\mathrm{L})$; those that protect the ribosomes from the action of tetracycline, genes tet $(\mathrm{M}) \operatorname{tet}(\mathrm{O})$ tet $(\mathrm{Q})$; and gene tet $(\mathrm{X})$ that encodes a protein able to inactivate the antibiotic drug ${ }^{16}$. In Gram-positive cocci, the concomitant presence of two or more genes tet is common but this peculiarity was not confirmed in the present study, since only 5 isolates $(17.2 \%)$ of enterococci expressed simultaneously tet $(\mathrm{K})$ and tet(M) determinants.

In Enterobacteriaceae, the most common tetracycline resistance markers were tet(A) and $\operatorname{tet}(B)$, which were present in $45.8 \%$ of the tetracycline resistant isolates, according to previous studies ${ }^{1,11,12,16}$. In enterococci, genes tet $(\mathrm{K})$ and $\operatorname{tet}(\mathrm{M})$ represented $58.6 \%$ of the detected resistance markers.

Heterogeneity of tetracycline resistance genes in Gram-negative enteric rods and enterococci was significant, as also previously reported ${ }^{11}$, although these genes were not detected in 18 enteric resistant isolates. There are several possible explanations for the non-detection of tet genes in $23.4 \%$ of our resistant isolates. The most probable possibility is that we screened only 12 of the 38 recognized tet genes and some isolates present an inherent resistance to tetracycline as opposed to acquired resistance.

\section{ACKNOWLEDGMENTS}

This study was partially supported by grants of Fundação de Amparo à Pesquisa do Estado de São Paulo (FAPESP, 07/54851-0).

\section{REFERENCES}

1- Aminov RI, Garrigues-Jeanjean N, Mackie RI. Molecular ecology of tetracycline resistance: development and validation of primers for detection of tetracycline resistance genes encoding ribosomal protection proteins. Appl Environ Microbiol. 2001;67:22-32.
2- Barbosa FCB, Mayer MPA, Saba-Chujfi E, Cai S. Subgingival occurrence and antimicrobial susceptibility of enteric rods and pseudomonads from Brazilian periodontitis patients. Oral Microbiol Immunol. 2001;16:306-10.

3- Belaaouaj A, Lapoumeroulie C, Caniça MM, Névot GVP, Krishnamoorthy R, Paul G. Nucleotide sequences of the genes coding for the TEM-like $\beta$-lactamases IRT-1 and IRT-2 (formerly called TRI-1 and TRI-2). FEMS Microbiol Lett. 1994;120:75-80.

4- Daniluk T, Fiedoruk K, Eciepuk M, Zaremba ML, Rozkiewicz $D$, Cylwik-Rokicka D, et al. Aerobic bacteria in the oral cavity of patients with removable dentures. Adv Med Sci. 2006;51:86-90. 5- Gaetti-Jardim Jr E, Landucci LF, Lins AS, Vieira EMM, Oliveira $\mathrm{SR}$. Susceptibility of strict and facultative anaerobes isolated from endodontic infections to metronidazole and $\beta$-lactams. J Appl Oral Sci. 2007; 15:539-45.

6- Gaetti-Jardim E Jr, Nakano V, Wahasugui TC, Cabral FC, Gambá $\mathrm{R}$, Avila-Campos MJ. Occurrence of yeasts, enterococci and other enteric bacteria in subgingival biofilm of HIV-positive patients with chronic gingivitis and necrotizing periodontitis. Braz J Microbiol. 2008;39:257-61.

7- Gonçalves MO, Coutinho-Filho WP, Pimenta FP, Pereira GA, Pereira JAA, Mattos-Guaraldi AL, et al. Periodontal disease as reservoir for multi-resistant and hydrolytic enterobacterial species. Lett Appl Microbiol. 2007;44:488-94.

8- Henriques IS, Fonseca F, Alves A, Saavedra MJ, Correia A. Occurrence and diversity of integrons and â-lactamase genes among ampicillin-resistant isolates from estuarine waters. Res Microbiol. 2006;157:938-47.

9- Livermore DM. $\beta$-Lactamases in laboratory and clinical resistance. Clin Microbiol Rev. 1995;8:557-84.

10- Luzzaro F, Mezzatesta M, Mugnaioli C, Perilli M, Stefani S, Amicosante $G$, et al. Trends in production of extended-spectrum $\beta$-lactamases among enterobacteria of medical interest: report of the second Italian nationwide survey. J Clin Microbiol. 2006;44:1659-64.

11- Macauley J], Adams CD, Mormile MR. Diversity of tet resistance genes in tetracycline resistant bacteria isolated from a swine lagoon with low antibiotic impact. Can J Microbiol. 2007;53:130715.

12- Ng L-K, Martin I, Alfa M, Mulvey M. Multiplex PCR for the detection of tetracycline-resistant genes. Mol Cell Probes. 2001;15:209-15.

13- Pérez-Pérez FJ, Hanson ND. Detection of plasmid-mediated AmpC $\beta$-lactamase genes in clinical isolates by using multiplex PCR. J Clin Microbiol. 2002;40:2153-62.

14- Pitout JDD, Nordmann P, Laupland KB, Poirel L. Emergence of Enterobacteriaceae producing extended-spectrum $\beta$-lactamases (ESBLs) in the community. J Antimicrob Chemother. 2005;56:52-9. 15- Rice LB, Bellais S, Carias LL, Hutton-Thomas R, Bonomo RA, Caspers $\mathrm{P}$, et al. Impact of specific $p b p 5$ mutations on expression of $\beta$-lactam resistance in Enterococcus faecium. Antimicrob Agents Chemother. 2004;48:3028-32.

16- Roberts MC. Tetracycline resistance determinants: mechanisms of action, regulation of expression, genetic mobility, and distribution. FEMS Microbiol Rev. 1996;19:1-24.

17- Silva MF, Vaz-Moreira I, Gonzalez-Pajuelo M, Nunes OC, Manaia $\mathrm{CM}$. Antimicrobial resistance patterns in Enterobacteriaceae isolated from an urban wastewater treatment plant. FEMS Microbiol Ecol. 2007;60:166-76.

18- Sixou M. Diagnostic testing as a supportive measure of treatment strategy. Oral Dis. 2003;9:54-62.

19- Spanu T, Luzzaro F, Perilli M, Amicosante G, Toniolo A, Fadda $G$, et al. Occurrence of extended-spectrum $\beta$-lactamases in members of the family Enterobacteriaceae in Italy: implications for resistance to $\beta$-lactams and other antimicrobial drugs. Antimicrob Agents Chemother. 2002;46:196-202. 